FACULDADE ESTÁCIO DE SÃO LUÍS

COORDENADORIA DO CURSO DE BIOMEDICINA

CURSO DE BIOMEDICINA

PREVALÊNCIA DE ANTICORPOS IRREGULARES EM DOADORES DE SANGUE ATENDIDOS PELO CENTRO DE HEMATOLOGIA E HEMOTERAPIA DO MARANHÃO

São Luís - MA

2019 


\author{
CICERO WALLIKON BEZERRA DE LIMA \\ JEZREEEL SILVA ALVES \\ KELL BRENNO LOPES ARAGÃO \\ MARCIA FERNANDA MENDES DOS SANTOS
}

\title{
PREVALÊNCIA DE ANTICORPOS IRREGULARES EM DOADORES DE SANGUE ATENDIDOS PELO CENTRO DE HEMATOLOGIA E HEMOTERAPIA DO MARANHÃO
}

\author{
Trabalho de conclusão de curso, apresentado a \\ Faculdade Estácio de São Luís, como parte das \\ exigências para a obtenção do título de graduação. \\ Orientadora: Prof.a. D.ra. Dinaura Maramaldo Cruz
}

São Luís - MA 


\author{
CICERO WALLIKON BEZERRA DE LIMA \\ JEZREEEL SILVA ALVES \\ KELL BRENNO LOPES ARAGÃO \\ MARCIA FERNANDA MENDES DOS SANTOS
}

\title{
PREVALÊNCIA DE ANTICORPOS IRREGULARES EM DOADORES DE SANGUE ATENDIDOS PELO CENTRO DE HEMATOLOGIA E HEMOTERAPIA DO MARANHÃO
}

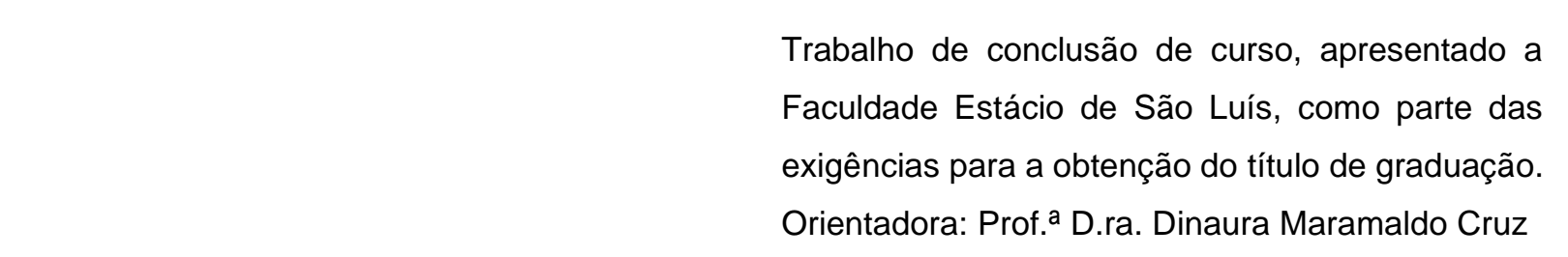

Aprovado em

BANCA EXAMINADORA

Prof. ‥ Dra. Dinaura Maramaldo Cruz (Orientadora)

Doutora em Saúde Pública - UAA

Faculdade Estácio de São Luís

Prof ${ }^{a}$ Ericka Miranda Mesquita

Mestre em Biologia Parasitária - CEUMA

Faculdade Estácio de São Luís 


\section{SUMÁRIO}

1. INTRODUÇÃO

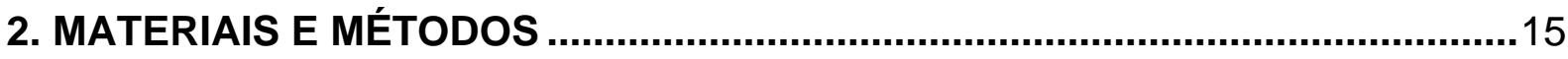



2.2 Amostra e coleta de dados.........................................................................



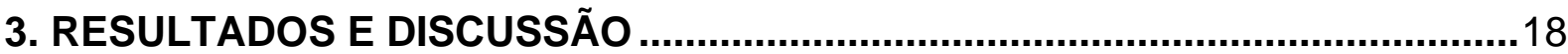

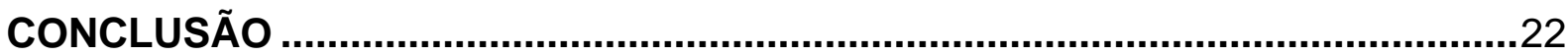

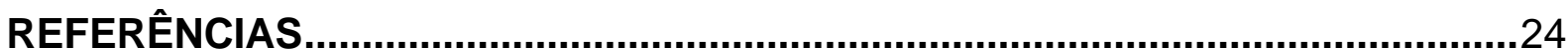

APÊNDICE

ANEXO 
Dedicamos este trabalho ao professor José de Jesus Rodrigues Marques, que nos auxiliou com a germinação das ideias sobre este tema, e sua motivação que foi essencial para a construção de nossa pesquisa. 


\section{AGRADECIMENTOS}

Este trabalho encerra uma longa e importante etapa da minha formação acadêmica. Dessa forma gostaria de exprimir a minha eterna gratidão a Tania Maria Bezerra de Lima, uma mãe maravilhosa, que com esforço, dedicação e trabalho contribui significantemente para minha educação e consequentemente a realização dos meus sonhos.

(Cicero Walllikon Bezerra de Lima)

Agradeço a Deus por ter me fortalecido ao ponto de superar as dificuldades e também por toda saúde que me deu e me permitiu alcançar essa etapa tão importante da minha vida. Aos professores eu agradeço a orientação incansável, o empenho e a confiança que ajudaram a tornar possível este sonho tão especial. Á minha família e amigos que nunca desistiram de mim e sempre me ofereceram amor, eu deixo uma palavra e uma promessa e gratidão eterna. A as pessoas que de alguma forma fizeram parte do meu percurso, agradeço a todos de coração.

Kell Breno Lopes Aragão)

Agradeço a mim, por nunca desistir e por sempre acreditar na minha capacidade, agradeço por apesar das dificuldades, tenho me mantido firme mesmo quando estava fraco, agradeço por ter conseguido chegar até aqui nos meus estudos, mesmo cuidando da minha mãe já idosa e com saúde fragilizada e o mesmo tempo, tendo que conciliar trabalho e estudo, mesmo estando com depressão, agradeço a mim, por está terminando mais um ciclo da minha vida. Agradeço a minha mãe por ser a única pessoa nessa terra que meu deu todas as condições para eu chegar até aqui.

(Jezreel Silva Alves)

Agradeço a Deus pelo o que Ele tem feito por mim durante todos esses anos, sou grata pelo pai que tenho, Francisco Santos e minha avó Francisca Rodriguês, aos meus irmãos Giselle Santos; Rarissa Danielle e Renan Santos que sempre estiveram comigo quando mais precisei, me incentivando e me encorajando em cada momento. 
Agradeço todo amor e dedicação, se não fosse pelo sacrifício e esforço de vocês eu não estaria concluindo mais essa etapa da minha vida.

As minhas melhores amigas da graduação: Méssia e Élida, obrigada por fazerem parte disso, aprendi muito com vocês, compartilhamos momentos de alegrias, tristezas, ansiedade, nervosismo, mas vencemos! Agradeço aos meus colegas de tcc: Cicero o Breno e o Jezreel, pois nesta conclusão de ciclo, ambos já fazem parte da minha história acadêmica, desejo sucesso para todos. Agradeço também o meu noivo João Batista Costa pelo apoio e dedicação em todas as fases da minha graduação.

Até aqui nos ajudou o Senhor. 1Sm:7.12!

(Marcia Fernanda Mendes dos Santos) 
"O futuro pertence àqueles que acreditam na beleza de seus sonhos." (Eleanor Roosevelt) 


\title{
PREVALÊNCIA DE ANTICORPOS IRREGULARES EM DOADORES DE SANGUE ATENDIDOS PELO CENTRO DE HEMATOLOGIA E HEMOTERAPIA DO MARANHÃO
}

\section{PREVALENCE OF IRREGULAR ANTIBODIES IN BLOOD DONORS ATTENDED BY THE CENTER OF HEMATOLOGY AND HEMOTHERAPY OF MARANHÃO}

\author{
Cicero Wallikon Bezerra de Lima ${ }^{1}$; Jezreel Silva Alves ${ }^{1}$; Marcia Fernanda Mendes \\ dos Santos ${ }^{1}$; Kell Brenno Lopes Aragão'; Dinaura Maramaldo Lopes²
}

\begin{abstract}
RESUMO
A diversidade antigênica das células eritrocitária é uma das causas da formação dos anticorpos irregulares de importância na clínica transfusional, esses anticorpos estão livres no soro ou plasma do doador de sangue e ocorrem devido à uma sensibilização conta antígenos dos Sistemas Rh, Kell, Duffy, Kidd, Lewis, P, MNS, Luth e Dia. O presente estudo tem como objetivo identificar a prevalência de anticorpos irregulares em doadores de sangue, no Hemomar de São Luís do Maranhão. Foi realizado um estudo retrospectivo, descritivo, quantitativo partindo-se do registro de planilha eletrônica do sistema de informação do Hemocentro O presente, caracterizou - se como estudo retrospectivo, descritivo, quantitativo partindo - se do registro de planilha eletrônica do sistema de informação do Hemocentro Coordenador - HEMOMAR entre os anos de 2017 a 2018, e o método utilizado para essa comprovação; consiste na reação de aglutinação antígeno-anticorpo in vitro, tendo como metodologia o Gelcentrifugação (LISS e enzima), utilizando-se o diluente 2 - LISS modificado para suspensão de hemácias, o cartão LISSICommbs (anti-IgG + c3d) e ID-DIAcell I e II hemácias em suspensão a $0,8 \%$ para pesquisa de anticorpos. Foram totalizados 46993 doadores de sangue e observou-se a frequência de anticorpos irregulares de $253(0,28 \%)$, sendo os três anticorpos mais frequentes anti-M (24,51\%), anti-D $(14,62 \%)$ e anti-E $(6,32 \%)$. Independentemente do número de doações de sangue, existe uma frequência de anticorpos antieritrocitários irregulares na população, com frequência de $0,28 \%$, semelhantes a outros estudos com mesmo tipo de população.
\end{abstract}

Palavras-chaves: Prevalência; Aloanticorpo; P.A.l; Hemomar.

\section{ABSTRACT}

The genetic genetics of erythrocyte cells is one of the causes of infection of microorganisms in the transfusion process, people are free of serum or plasma donor blood and the tissue is one of the most sensitive antigen technologies Rh, Kell, Duffy, Kidd, Lewis, P, MNS, Luth and Dia. The present study aimed to determine the presence of a disease in blood donors, not Hemomar of São Luís do Maranhão. A retrospective, descriptive and quantitative study was carried out on the electronic program of the Hemocenter. The present study was characterized as a retrospective, descriptive and quantitative study, starting from the electronic spreadsheet register of the Hemocenter 's information system. Coordinator - HEMOMAR between the years 2017 to 2018, the style used for this proof; in the antigen-antibody agglutination reaction in vitro, using the Gel-

\footnotetext{
1 Graduandos em Biomedicina pela Faculdade Estácio de São Luís.

${ }^{2}$ Docente da Faculdade Estácio de São Luís, Doutora em Saúde Pública- UAA
} 
centrifugation (LISS and enzyme) method, using the modified 2-LISS diluent for red cell suspension, the LISS \Commbs card (anti-IgG + c3d) and ID-DIAcell I and II - $0.8 \%$ suspension red cells for antibody screening. A total of 46993 blood donors and a sudden frequency of precordial drug use of $253(0.28 \%)$, or more frequent anti-M $(24.51 \%)$, anti$D(14.62 \%)$ and anti- E (6.32\%). Regardless of the number of blood tests, there is a frequency of irregular antiepithelial antibodies in the population, often $0.28 \%$, similar to other studies with the same population type.

Keywords: Prevalence; Alloantibody; P.A.I.; Hemomar. 


\section{INTRODUÇÃO}

A diversidade antigênica das células eritrocitária é uma das causas da formação dos anticorpos irregulares, de importância na clínica transfusional (GIRELLO, KUHN, 2007).

O Sistema $A B O$ é o mais importante e mais conhecido sistema de grupos sanguíneos. Na prática hemoterápica deve ser evitado transfundir sangue que contenha um antígeno $A B O$ ao receptor que não o possua, pois, uma transfusão incompatível tem como consequência reações transfusionais hemolíticas intravasculares, podendo levar o paciente ao óbito. Além dos antígenos $A B O$, outros também são encontrados na porção extracelular da membrana das hemácias e podem ser do tipo carboidrato, proteína ou glicoproteína. São conhecidos 328 antígenos de diferentes grupos sanguíneos, 282 dos quais estão organizados em 30 sistemas, nos quais importantes ações e funções são desempenhadas por estes antígenos, tais como: transportadores (sistemas Diego, Kidd e Colton), receptores e moléculas de adesão (sistemas Duffy e MNS), enzimática (sistemas Kell) (OLIVEIRA, RIBEIRO, VIZZONI, 2013).

O Linfócito $\mathrm{B}$ em contato com um antígeno $(\mathrm{Ag})$ específicos (bactérias, fungos ou vírus), procura correspondentes derivados, sendo diferenciados a partir da célula primordial linfóide em plasmócitos secretores de imunoglobulinas (anticorpos). As imunoglobulinas (Igs) dividem-se em cinco grupos ( $\lg G, \lg M, \lg A, \lg D$ e $\lg E$ ) sendo sua função a ligação ao antígeno; ativação do sistema complemento e fixação a receptores celulares. Os anticorpos (glicoproteínas com função imunitária) sintetizados por linfócitos $\mathrm{B}$ e plasmócitos, são encontrados em fluidos biológicos como plasma/soro sanguíneo e secreções mucosas, ou ancorados na membrana de Linfócitos B (Receptores de Linfócitos B - BCR). Sendo indispensáveis como mediadores a Resposta Imune Adquirida Humoral, que reagem especificamente com os antígenos estimulando a sua produção (VERRASTRO, LORENZI E NETO, 2005).

Os anticorpos antieritrocitários são produzidos contra um ou mais epítopo presentes nas superfícies dos eritrócitos, e são classificados como regulares e irregulares. Os anticorpos regulares estão presentes na totalidade da população portadora de um fenótipo especifico, como do sistema sanguíneo $A B O$; os irregulares são anticorpos inesperados, produzidos por uma parcela de indivíduos de 
determinado fenótipo podendo natural ou imune. Os de natureza imune são produzidos a partir de contato com antígenos desconhecido (GIRELLO, KUHN, 2016).

O Sistema Sanguíneo ABO é o único em que o anticorpo esta naturalmente presente no soro do sangue, sendo produzido a partir de antígenos do próprio sistema $A B O$, esses anticorpos são inexistentes ao nascimento e após os quatro meses de vida tornam-se detectáveis. A presença de anticorpos no soro, contra os antígenos dos sistemas Rh, Kell, Duffy, Kidd, Lewis, P, MNS, Lutheran e Diego acontecem de forma não natural decorrentes de uma sensibilização ao sangue do indivíduo (BRASIL,2014).

O Sistema Rh, ao contrário do que ocorre com o sistema $A B O$, os $A c$ (antígenos) não existem de forma natural no soro. São predominantemente $\lg G$ e não fixam complemento. Esses são encontrados em casos de imunização com antígenos do sistema Rh (em casos de transfusões incompatíveis e em gestações, cujos fetos apresenta especificidade $\mathrm{Rh}$ diferente da mãe). Os anticorpos dirigidos para os antígenos do Sistema Duffy, anti-Fya (relativamente raro), e anti-Fyb, são em maioria imune, pertencem ao isótopo $\lg G$, podendo ser encontrado alguns naturais do isótopo IgM, porém passiveis de causar reação transfusional e DHPN - Doença Hemolítica do Recém-Nascido (OLIVEIRA, RIBEIRO, VIZZONI, 2013).

Os anticorpos anti-M e anti- $N$, são anticorpos de imunização presentes no soro a partir da reação contra antígenos do Sistema $\mathrm{MN}$, segundo maior sistema imunogênico após o Rh e de ocorrência natural. Os antígenos do MNSs podem ser identificados após a $9^{\mathrm{a}}$ semana de gestação, o anti-M é de classe lgG (reativos em baixa temperatura $-4^{\circ} \mathrm{C}$ ), são de pouco importância transfusional, porém se raramente reativos a $37^{\circ} \mathrm{C}$ podem promover reações transfusionais sérias. $\mathrm{M}$ e $\mathrm{N}$ são basicamente antígenos eritrocitários e estão localizados no cromossomo, posteriormente passou-se a ser chamar Sistema MNSs, em decorrência da descoberta do antígeno S e o alelo "s" (BONIFÁCIO, NOVARETTI, 2019).

O Sistema Kell, está presente na superfície das hemácias do sangue, tornouse descoberto em 1946 depois da implementação da técnica de Coombs. Foram relatados até o momento 23 antígenos associados a esse sistema sendo o terceiro mais importante imunogênico, os mais importantes são Kell (K ou K1) e Cellano (k ou K2). O seu correspondente antagônico ao Kell é o anti-K, em bancos de sague são anticorpos de classe lgG, ativam complemento, e em baixa frequência são do tipo lgM. O Anti-Ke Anti-k podem ocasionar reações transfusionais graves imediatas ou tardias, 
pois podem persistir no organismo por anos (reação hemolítica pós transfusional) e DHPN grave (ROJAS, ESPINOSA, ESPINOZA ET AL, 2015).

Em 1955 na Venezuela, surge o Grupo Sanguíneo Diego, formado pelos antígenos mais expressivos $\mathrm{Di}^{\mathrm{a}} / \mathrm{Di}^{\mathrm{b}}$ e Wra / Wrb e por outros 17 antígenos menos expressivos, em decorrência de um caso de recém-nascido com DHPN em que a mãe apresentava um anticorpo corresponde a este grupo sanguíneo. Existe a possibilidade de três genótipos para o sistema Diego: Di $(a-b+)$, Di $(a+b+)$ e Di $(a+b-)$. A sensibilização ocorre quando por meio de transfusão ou gestação, as hemácias com antígeno Dia (genótipo a- b+), produzem anticorpo anti-Dia (classe IgG), provocando em contrapartida reações transfusionais e doenças hemolíticas perinatais por incompatibilidade materno-fetal (SILVA, JORGE E HIRTSCH, 2004).

Com um número significativo de antígenos o Sistema Lutheran, possui 24 antígenos reconhecidos pela Sociedade Internacional de Transfusão, os anticorpos Anti-Lua e Anti-Lub tenderm a ser respectivamente do tipo IgG e IgM. A moléculas contendo Lutheran podem estar presentes em hemácias de pacientes com anemia falciforme (JUNQUEIRA, CASTILHO, 2002)

De acordo com Baiochii, Nardozza (2009, on-line):

A aloimunização é a formação de anticorpos quando há a exposição do indivíduo a antígenos não próprios como ocorre, por exemplo, na transfusão de sangue incompatível e nas gestantes, cujos fetos expressam em suas células sanguíneas antígenos exclusivamente de origem paterna.

Os anticorpos devem ser levados em consideração quando realizamos transfusões sanguíneas, devido a sua atividade dentro do sistema imune e em particular o aloanticorpo (anticorpo irregular), pois este foi sintetizado em decorrência de antígenos eritrocitários. Devemos salientar que a presença de anticorpos antieritrocitários em transfusões sanguíneas, sensibilizam esses receptores causando a aloimunização (BRASIL, 2017).

Castilho (2008), descreve que o efeito indesejável mais grave diretamente associado às transfusões é aquele que resulta em hemólise do sangue transfundido devido a anticorpos pré-formados presentes no plasma do receptor. O significado clínico dos anticorpos antieritrocitários depende da incidência do antígeno, sob influência de diferentes origens étnica, da sua imunogenicidade e de situações clínicas específicas.

A identificação destes anticorpos, ou fenotipagem eritrocitária é essencial para que esta aloimunização não aconteça. A Portaria de Consolidação de № 5; que institui 
os procedimentos técnicos e hematológicos, na seção IV sobre a obrigatoriedade do teste de pesquisa de anticorpos irregulares diz quer:

Art. 117. O serviço de hemoterapia realizará os seguintes exames imunohematológicos para qualificação do sangue do doador, a fim de garantir a eficácia terapêutica e a segurança da futura doação: (Origem: PRT MS/GM 158/2016, Art. 118) I - tipagem ABO; (Origem: PRT MS/GM 158/2016, Art. 118, I) II - tipagemRhD; e (Origem: PRT MS/GM 158/2016, Art. 118, II) III pesquisa de anticorpos antieritrocitários irregulares. (Origem: PRT MS/GM 158/2016, Art. 118, III) (BRASIL, 2017, [s.p.]).

Testes sorológicos como o Coombs Indireto; também conhecido por Pesquisa de Anticorpos Irregulares (P.A.I), devem ser capazes de detectar anticorpos clinicamente significativos e devem incluir a incubação a $37^{\circ}$ e o uso do soro antiglobulina humana (anti-lgG ou poliespecífico), são solicitados pelos hemocentros e bancos de sangue, e são essenciais para evitar a contaminação com agentes infeciosos garantindo uma ação preventiva em compatibilidade transfusional ao paciente (BRASIL, 2014).

A portaria MS/GM 158/2016, art. 177, capítulo 18 recomenda que:

A realização da fenotipagem para os antígenos eritrocitários no sangue do receptor, dos sistemas Rh (E, e, C, c), Kell (K), Duffy (Fya, Fyb), Kidd (Jka, $\mathrm{Jkb})$ e MNS (S, s), para pacientes aloimunizados contra antígenos eritrocitários ou que estão ou poderão entrar em esquema de transfusão crônica, com o objetivo de auxiliar a identificação de possíveis anticorpos antieritrocitários irregulares. (BRASIL, 2016, [s.p.])

No Maranhão o órgão responsável pela condução da política estadual de sangue e Hemocomponentes é o Centro de Hematologia e Hemoterapia do Maranhão (Hemomar), seguindo as diretrizes da Resolução da Diretoria Colegiada (RDC), atualizada de $\mathrm{N}^{\circ} 158$ de 04 de fevereiro de 2016. Tem por missão oferecer serviços de Hemoterapia e Hematologia em toda a Rede Estadual de Saúde do Estado do Maranhão. Além da unidade em São Luís, o Hemomar conta com sete bancos de apoio especializados nesta área, distribuídos no interior do Estado de Maranhão, a saber: Imperatriz, Balsas, Caxias, Pinheiro, Santa Inês, Bacabal e Pedreiras (BRASIL, 2016)

A transfusão sanguínea é uma terapia onde há a possibilidade de riscos à saúde, levando o paciente a ter diversos tipos de reações transfusionais por procedimentos falhos, inadequados ou até mesmo omissões. Vê-se de forma essencial a pesquisa de anticorpos irregulares (P.A.I.), como um procedimento eficaz que garante através do rastreio aos doadores de sangue; detectar eventuais 
aloimunizações, que poderiam ser produzidos por sensibilizações a antígenos estranhos durante as transfusões de hemoderivados do sangue.

O presente estudo tem como objetivo identificar a prevalência de anticorpos irregulares em doadores de sangue, no Hemomar de São Luís do Maranhão.

\section{MATERIAIS E METÓDOS}

2. 1 Tipo e período de estudo

O presente, caracterizou-se como estudo retrospectivo, descritivo, quantitativo partindo-se do registro de planilha eletrônica do sistema de informação do Hemocentro Coordenador - HEMOMAR.

Foram inclusas todas as amostras de doadores de sangue submetidos à Pesquisa de Anticorpos Irregulares no período de 2017 a 2018.

\subsection{Amostragem e Coleta de dados}

A amostragem do estudo constituiu - se de todas amostras testadas em doadores de sangue no período de 2017 a 2018.

Realizou - se a coleta de dados mediante planilha elaborada pelos autores, a qual contemplava quantitativo mensal e identificação do anticorpo, conforme protocolo de rotina do Hemocentro.

O Hemocentro realiza análise das amostras após a doação de sangue. De cada doador são coletados quatro tubos a vácuo, e um deles contendo EDTA é encaminhado para o laboratório de Imuno-hematologia de doador; este utiliza a metodologia em Gel por automação em sua rotina de procedimento operacional e as amostras com presença positiva para anticorpos irregulares são identificadas para os sistemas sanguíneas: Rh, Kell, Duffy, Kidd, Lewis, P, MNS, Luth e Dia com uso de painel de identificação da Biorad.

De acordo com a metodologia adotada pelo Hemomar e descrita no POP (ANEXO A) o princípio do teste consiste na reação de aglutinação antígeno-anticorpo in vitro, em Gel-centrifugação em meio isotônico e enzimático (LISS e enzima). São utilizados: diluente 2 - LISS modificado para suspensão de hemácias (figura 1A); cartão LISSICoombs (anti-IgG + c3d) (figura 1B); ID-DIAcell I e II - hemácias em suspensão a 0,8\% para pesquisa de anticorpos (figura 1C). 
Figura 1 - Reagentes utilizados na metodologia Gel Centrifugação para P.A.I. no HEMOMAR-MA (1A), ID-Diluente 2, para suspensa de hemácias (2B) - Cartão LISS/Coombs (ANTI-Gg+C3d) e (3C) - IDDIAcell I e II a $8 \%$



Fontewww.bio-rad.com/pt-bx/product id-diacell-i-ii? $? \mathrm{D}=\mathrm{LO}$ E HQ2CB

A interpretação e expressão do resultado consiste na reação positiva quando as hemácias serão retiradas pelo gel e ficaram suspensas no microtúbulo e pela reação negativa, quando as hemácias passam através do gel e ficam dispersas no fundo do microtúbulo (Figura 2A).

O teste P.A.I apenas identifica a presença ou ausência de antígeno irregular, sendo positiva a presenças de anticorpo irregular nas hemácias I ou II (ou em ambas) é necessário identificar o Anticorpo Irregular - I.E.I usando o painel em gel da BioRad. Está metodologia determina a especificidade do anticorpo irregular detectado nas amostras de soro/plasma de doadores de sangue por ocasião da pesquisa de anticorpo irregular positiva. (Anexo B).

O procedimento para a realização do Painel em gel da BioRad consiste em utilizar:

1. O diluente 2 - LISS modificado para suspensão de hemácias (Figura $2 A)$; 
2. Cartão LISS/Coombs (Anti-IGg + c3d) (figura 5) (Figura 2B);

3. ID - Dia Painel - Hemácia teste para identificação de anticorpos - kit com 11 frascos, contendo os 11 antígenos respectivamente da classe Rh-hr, Kell, Duffy, Kidd, Lewis, P, MNS, Lutheran e Diego (Figura 2C);

Os resultados obtidos são transcritos em cruzes para uma tabela de antígenos da ID-Dia painel BioRad (ANEXO C) e interpretados.

Figura 2 - Resultado negativo e positivo para reação de aglutinação antígeno-anticorpo in vitro; no cartão em gel (A), Cartão LISS/Coombs que consiste em 6 microtubos contendo anti-IgG e anti-C3d dentro da matriz de gel (B) e Kit de 11 frascos com Hemácia teste para identificação de anticorpos /ID - Dia Painel (C).

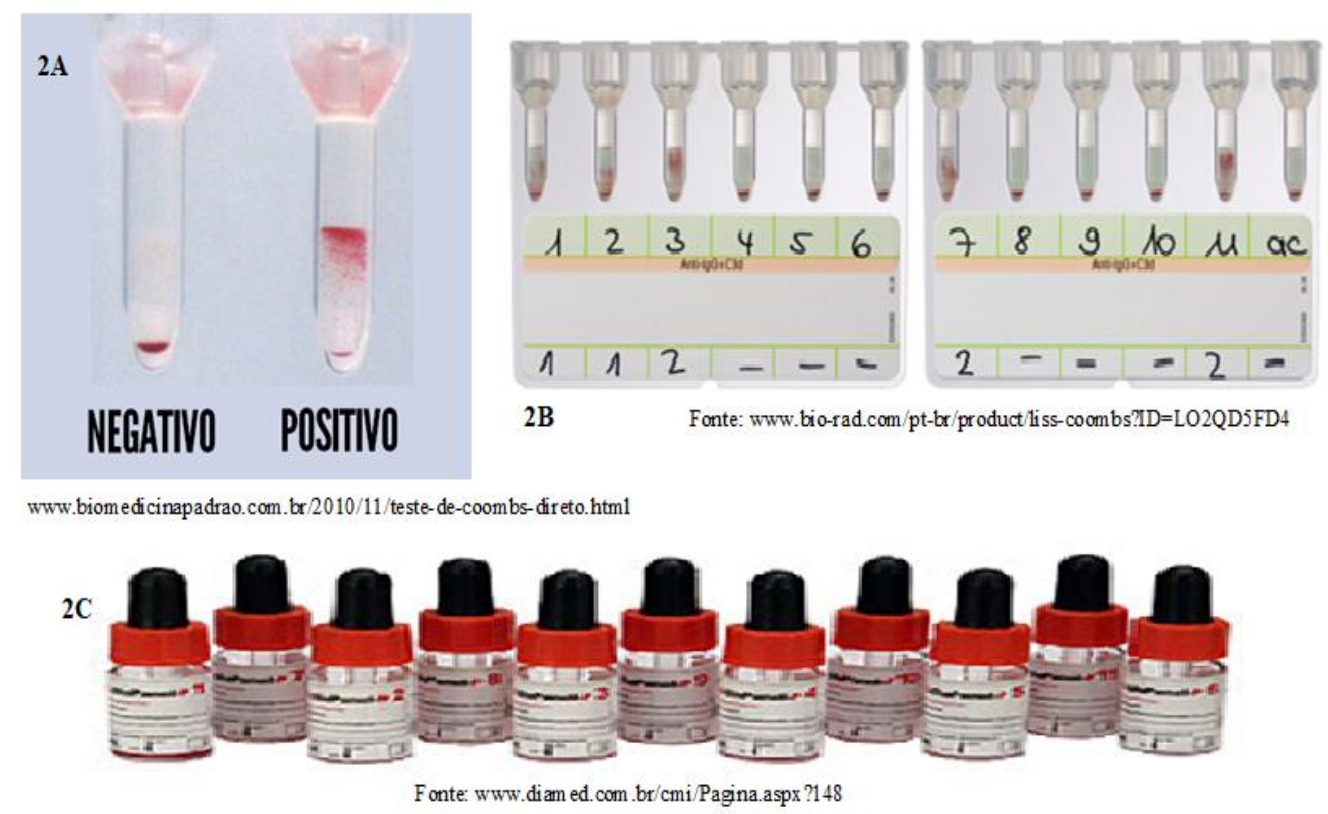

\section{3 Aspectos éticos}

Os aspectos éticos do estudo foram respeitados seguindo as diretrizes da Resolução no 466, de 12 de dezembro de 2012, do Conselho Nacional de Saúde, sendo aprovado pela coordenação de ensino e pesquisa - Hemomar e anuência da Coordenação de Laboratórios - HEMOMAR. 


\section{3- RESULTADOS E DISCURSÁO}

No período proposto para a pesquisa observou-se que o Hemomar analisou 46.993 amostras em 2017 e 43.829 amostras em 2018 e a frequência de PAI positivo foi $0,27 \%$ e $0,25 \%$ respectivamente (Gráfico 1 ), sendo que a média mensal de reações positivas foram iguais ( $m=10,51 \mathrm{PAl}$ positivos / mês), entretanto identificou - se uma variação dos casos em meses pontuais, embora o número de amostras testadas seja aproximadamente igual nestes meses (Apêndice - tabela coleta mensais)

Gráfico 1 - Número de testes P.A.I realizados entre os anos de 2017 a 2018 pelo Hemomar.

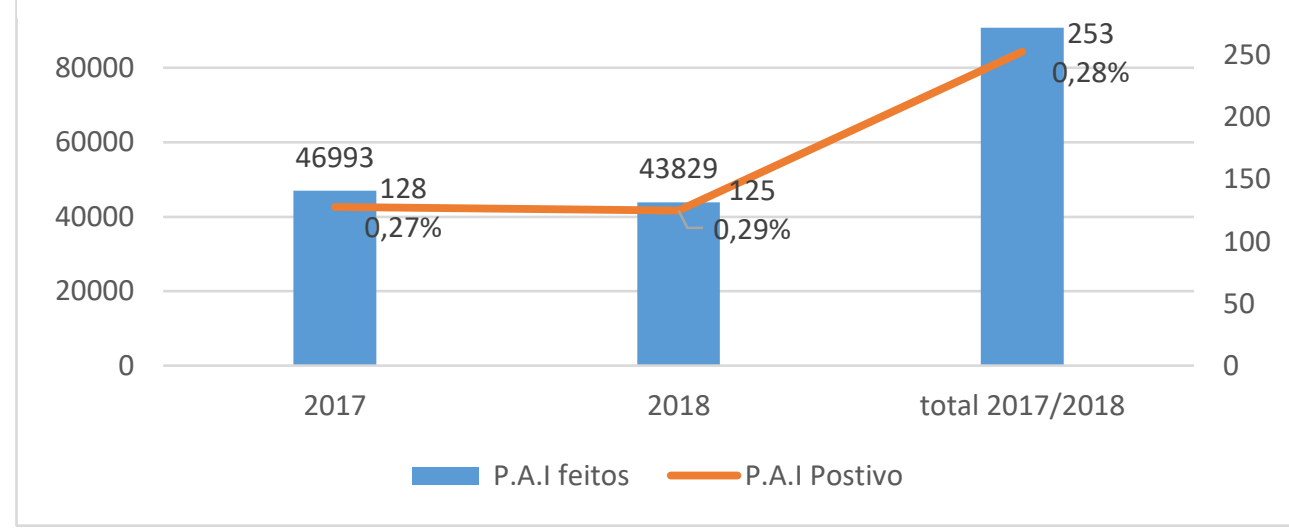

Fonte: Elaborado pelos autores, 2019

O total de $253(0,28 \%)$ amostras positivas para presença de anticorpos irregularesno sangue do doador, corrobora com dados da literatura que descrevem prevalência de 0,3 a 2\% entre doadores de sangue (CASTILHO, 2008; KOURY,2018).

Santos (2007), ressalta que sem a realização deste teste, existiria o risco de reação transfusional; de aloimunização dos receptores de sangue, através da sensibilização de antígenos eritrocitários. A regulamentação de hematerapia no Brasil, recomenda que a transfusão de sanguínea de hemocomponentes do sangue deve ser feita de forma criteriosa e obedecendo as normas técnicas, pois toda transfusão traz riscos ao receptor de forma imediato ou tardia (BRASIL, 2017).

Demonstra-se no gráfico 2 a distribuição mensal das doações de sangue e amostras analisadas, e a frequência de P.A.I positivos. As flutuações de frequência ocorrem no início dos semestres, a maior frequência ocorreu nos meses de fevereiro de $2017(0,40 \%)$ e março de 2018 (0,61\%), e tende a cair em meses pontuais, mantendo-se estável nos meses seguinte do segundo semestre, porém com 
decréscimo em dezembro de 2018 (0,08\%). Observa-se porem que em 2017 a menor captação e frequência de anticorpos irregulares ocorreu em março $(0,09 \%)$ do mesmo ano.

Gráfico 2 - Frequência mensal de testes Pesquisa de Anticorpos Irregulares em doadores de sangue do Hemomar no período de 2017 a 2018 - São Luís/MA



Fonte: Elaborado pelos autores, 2019

A Coordenação-Geral de Sangue e Hemoderivados (CGSH) do Ministério da Saúde, desenvolveu o Guia Nacional de Gerenciamento de Estoque de Sangue. Este guia orienta ações relativa a captação e gerenciamento relacionado aos estoques de sangue, para que toda polução tenha acesso aos Hemocomponentes e hemoderivados. Uma dessas ações estabelece que sempre que houver eventos especiais, como carnaval, festas juninas, grandes encontros religiosos e culturais, afim de evitar o desabastecimento ou possível aumento da demanda, deve-se, como medida preventiva realizar campanhas de incentivo a doação de sangue. A gestão de estoque deve prever períodos festivos bem como, aqueles relacionados ás férias. (BRASIL, 2011).

Dentre as amostras P.A.I positivo demonstra-se na tabela 1 a distribuição do perfil dos doadores de sangue quanto aos sistemas sanguíneos. Observou-se que dos 253 casos de aloimunizados, a maior prevalência de aloanticorpos contra determinados foi sistema MNSs (anti-M 24,51\%, $\mathrm{n}=62$ ), sistema Rh (anti-D 14,62\%, $\mathrm{n}=37$ e anti-E6,32\% $\mathrm{n}=6,32$ ). Os sistemas KELL e DIEGO apresentaram frequência de $3,56 \%$ (Anti-Kell) e 5,95\% (Anti-Di'), respectivamente. Foram detectados 63 casos 
de PAI indefinidos (24,9\%) e associação de anticorpos como as do anti-D e anti-C $(0,40 \%)$, entre diferentes anticorpos nas mostras de doadores de sangue; porém não houve diferença entre as frequências.

O anti-M reagem aos antígenos do sistema MNSs, é o mais comum deste sistema e em nossa pesquisa foi o mais encontrado (24,51\%). Os anticorpos do sistema MNSs (anti-M, anti-N, anti-S, anti-s e anti- $U$ ) podem ser anticorpos naturais ou imunes. $\mathrm{O}$ anti- $M$ é um anticorpo natural $(\lg M)$ e raramente reativos a $37^{\circ} \mathrm{C}$. $\mathrm{A}$ aloimunização deste anticorpo ocorre devido a transfusão sanguínea ou alimentação, porém a coleta de dados desta pesquisa refere-se a doadores de sangue, descartando a possibilidade de contagio por transfusões, evidenciando assim, a presença de uma população sensibilizada pelo antígeno do sistema MNSs (GIRELLO; KÜHN, 2016).

Tabela 1 - Frequência de aloanticorpos identificados em doadores atendidos no Hemomar no período de 2017 a 2018 - São Luis/MA

\begin{tabular}{|c|c|c|c|}
\hline SISTEMA/COLEÇÃO & TIPO DE & & \\
\hline DE GRUPO SANGUÍNEO & ANTICORPO & TOTAL & FREQUENCIA \% \\
\hline $\mathbf{R H}$ & Anti-D & 37 & $14,62 \%$ \\
\hline $\mathbf{R H}$ & Anti-C & 12 & $4,74 \%$ \\
\hline $\mathbf{R H}$ & Anti-E & 16 & $6,32 \%$ \\
\hline $\mathbf{R H}$ & Anti-c & 4 & $1,58 \%$ \\
\hline $\mathbf{R H}$ & Anti-C ${ }^{w}$ & 1 & $0,40 \%$ \\
\hline KELL & Anti-K & 9 & $3,56 \%$ \\
\hline LEWIS & Anti-Le ${ }^{a}$ & 16 & $6,32 \%$ \\
\hline $\mathbf{P}$ & Anti-P1 & 1 & $0,40 \%$ \\
\hline MNSs & Anti-M & 62 & $24,51 \%$ \\
\hline MNSs & Anti-S & 7 & $2,77 \%$ \\
\hline LUTHERAN & Anti-Lu ${ }^{a}$ & 5 & $1,98 \%$ \\
\hline DIEGO & Anti-Dia & 15 & $5,93 \%$ \\
\hline- & INDEFINIDOS & 63 & $24,90 \%$ \\
\hline ASSOCIAÇÕES & anti-Le ${ }^{\mathrm{a}}$ e anti-M & 1 & $0,40 \%$ \\
\hline ASSOCIAÇÕES & anti-D e anti-C & 1 & $0,40 \%$ \\
\hline ASSOCIAÇÕES & anti-E e anti-M & 1 & $0,40 \%$ \\
\hline ASSOCIAÇÕES & anti-Le $e^{a}$ e anti-Le ${ }^{b}$ & 1 & $0,40 \%$ \\
\hline ASSOCIAÇÕES & anti-D e anti-C & 1 & $0,40 \%$ \\
\hline TOTAL & & 253 & $100,00 \%$ \\
\hline
\end{tabular}

Fonte:

Elaborado pelos autores, 2019 
O Sistema RH (anti-D, anti-C,anti-E, anti-C, anti-e) é o mais complexo, seguido pelo MNSs, os aloanticorpos desse sistema são predominantemente lgG. No entanto observou - se que a predominância Anti-M (24,51\%), uma vez que segundo Eduardo e Luciano (2009), o antígeno Rh (D) está presente em torno de $85 \%$ dos indivíduos da raça branca, em 90 a $95 \%$ dos negros e praticamente em $100 \%$ dos amarelos e índios", ou seja, espera-se uma maior prevalência de anticorpos contra esse tipo de antígenos como o anti-D que em nosso estudo acometeu 37 casos (14,62\%), seguido pelo anti-E $(6,32 \%)$.

O sistema Rh está diretamente ligado a eritroblastose fetal, e acomete gestantes, causando uma incompatibilidade entre o fator Rh da mãe e 0 do feto, devido a presença de anticorpos antieritrocitários. Clinicamente é preocupante para uma segunda gravidez, caso a mulher tenha sido sensibilizada durante a primeira gravidez. Nos casos de transfusão de emergência, é recomendado o uso de hemácias "O" RhD negativos, porém caso não exista esse tipo de sangue em estoque, recomenda-se usar "O" RhD positivo em pacientes do sexo masculino ou acima de 45 anos em qualquer sexo. (BRASIL, 2014)

Quando o resultado para pesquisa de anticorpos antieritrocitários irregulares forem positivos, sugere-se a identificação da especificidade do anticorpo, mas nem sempre é possível identificar o anticorpo presente na amostra de soro, para que seja possível uma seleção segura de concentrados de hemácias fenotipados a serem transfundidos. Em nosso estudo detectou-se que os valores para anticorpos indefinidos $(24,90 \%)$, ou seja, que não foram possíveis de serem identificados ultrapassam aos do mais frequente (Anti-M 24,51\%) (BRASIL 2016).

Baptista, Nardin e Sthinghen (2011) relatam que a frequência de anticorpos irregulares evidenciado em seu estudo com pacientes, a correspondência foi de uma aloimunização para cada 673 transfusões; e os anticorpos de maior frequência foram o anti-K (14,3\%), anti-Dia $(9,5 \%)$, anti-M $(9,5 \%)$, anti-D (4,8\%) e anti-E $(4,8 \%)$.

A presença do anti-Dia em nosso estudo foi equivalente a $5,93 \%$, entretanto outros estudos destacam que estes anticorpos sendo da classe $\mathrm{lgG}$, está relacionado a aloimunizações decorrente de gestações ou transfusões e, também ligada a razões étnicas (KOURY,2018). No presente trabalho não foi possível avaliar variável sociodemográfica.

Identificou-se a frequência de 3,52\%, entretanto descreve Girello e Kuhn (2012), que o comportamento sorológico de anti-K, como os demais anticorpos do 
sistema Kell, geralmente de classe lgG, ser potente e ocasionar reações hemolíticas graves imediatas ou tardias, assim como DHPN grave.

Os riscos de uso de componentes sanguíneos com perfis de anticorpos irregulares, pode ser minimizado com uso de no futuro, a utilização de plataformas automatizadas e seguras de fenotipagem e/ou genotipagem em larga escala pode representar um grande avanço na segurança transfusional (CASTILHO, 2008).

É recomendado o uso de plasma (doador) compatível com as hemácias do paciente (receptor), pois evidenciando a aloimunização o procedimento padrão é o descarte das bolsas de plasma e plaquetas do doador, aproveitando-se o concentrado de hemácias, pois caso um paciente receba uma bolsa de plasma ou plaquetas contendo aloanticorpo, poderá ocorrer uma aglutinação, ou seja, o anticorpo do doador ira se ligar ao antígeno da hemácia. (BRASIL, 2016).

Regulamenta a Portaria de Consolidação № 5 de 3 de Outubro de 2017, no Art. $122, \S 1^{\circ}$ que os componentes sanguíneos que contenham anticorpos antieritrocitários irregulares devem ser rotulados como tais, e no $\S 2^{\circ}$, que as condições e situações nas quais os componentes de que trata o $\S 1^{\circ}$ podem ser utilizados ficarão a critério do responsável técnico de cada local, sendo, porém, recomendável que os componentes plasmáticos e os concentrados de plaquetas não sejam utilizados para transfusão (BRASIL, 2017); pois o anticorpos presentes no soro ou plasma sanguíneo podem acarretar reações hemolíticas quando infundidos nos receptores que apresentem os antígenos correspondentes (BRASIL, 2014)

\section{Conclusão}

No presente estudo conclui -se que:

1. Independentemente do número de doações de sangue, existe uma frequência de anticorpos antieritrocitários irregulares na população e está frequência sofre variações das características sociocultural da mesma

2. As variações evidentes foram nos primeiros meses do ano, mantendo se agosto e setembro, aumento assim a frequência da identificação destes anticorpos na população. 
3. Foram identificados anticorpos irregulares circulantes na população de São luís do Maranhão, com frequência de $0,28 \%$, semelhantes a outros estudos com mesmo tipo de população;

4. Os anticorpos identificados são clinicamente significativos;

5. A maior prevalência de aloanticorpos dos três principais anticorpos contra determinados antígenos do sistema MNSs (anti-M 24,51\%), Rh (anti-D e AntiE).

\section{REFERÊNCIAS}


BRASIL. Ministério da Saúde. Secretaria de Atenção à Saúde. Departamento de atenção Hospitalar e de Urgência. Imuno-Hematologia Laboratorial. Brasília, DF, 2014.

BAIOCHI, Eduardo; NARDOZZA, Luciano Marcondes Machado. Aloimunização. Revista Brasileira de Ginecologia e Obstetrícia, Rio de Janeiro, v. 31, n. 6, [s.p.], jun. 2009. Disponível em: $<$ http://www.scielo.br/scielo.php?script=sci_arttext\&pid=S010072032009000600008>. Acesso em: 03 abr. 2019.

BRASIL. Constituição (2017). Portaria de Consolidação no 5, de 28 de outubro de 2017. Brasília, DF, 11 dez. 2017.

Brasil. Ministério da Saúde. Secretaria de Atenção à Saúde. Departamento de Atenção Especializada. Guia nacional de gerenciamento de estoque de sangue em situações de emergência. Brasília : Ministério da Saúde, 2011.

BRASIL. Ministério da Saúde. Secretaria Executiva Departamento de Informática do SUS Processo de Documentação de Sistemas. Hemovida Produção de Hemocomponentes. Manual de Operação. Rio de Janeiro, RJ, 2016

BAIOCHI, E.; NARDOZZA, L. M. M. Aloimunização. Revista Brasileira de Ginecologia e Obstetrícia, Rio de Janeiro, v. 31, n. 6, [s.p.], jun. 2009. Disponível em: $\quad<h t t p: / / w w w . s c i e l o . b r / s c i e l o . p h p ? s c r i p t=s c i \_a r t t e x t \& p i d=S 0100$ 72032009000600008>. Acesso em: 20 mar. 2019.

BAPTISTA, M. W. G.; NARDIN, J. M.; STINGHEN, S. T. Aloimunização eritrocitária em pacientes de um hospital infantil atendido pelo Instituto Paranaense de Hemoterapia e Hematologia, de 2007 a 2010. Cadernos da Escola de Saúde, Curitiba, v. 2, n. 6, p.131-142, 2011.

BONIFÁCIO, S. L.; NOVARETTI, M. C. Z. Funções biológicas dos antígenos eritrocitários. Revista Brasileira de Hematologia e Hemoterapia, São Paulo, v. 31, n. 2, p.104-111, jan. 2009. Disponível em: <http://www.scielo.br/pdf/rbhh/v31n2/aop1509.pdf>. Acesso em: 02 mai. 2019.

CASTILHO, Lilian. O futuro da aloimunização eritrocitária. Revista Brasileira de Hematologia e Hemoterapia, São José do Rio Preto, v. 30, n. 4, [s.p.], jul. 2008. Disponível em: <http://www.scielo.br/scielo.php?script=sci_arttext\&pid=S151684842008000400003>. Acesso em: 10 jun. 2019.

GIRELLO A. L., KURHN T. I. B. Fundamentos da imuno-hematologia eritrocitária. $2^{\mathrm{a}}$ ed. São Paulo: SENAC, 2007.

GIRELLO A. L., KURHN T. I. B. Fundamentos da imuno-hematologia eritrocitária. 4ํㅡㄹ ed. São Paulo: SENAC, 2016. 
OLIVEIRA, M. B. S. C.; RIBEIRO, F. C.; VIZZONI, A. G. Conceitos básicos e aplicados em imuno-hematologia. Rio de Janeiro: EPSJV, 2013.

ROJAS, Marcela Vásquez; ESPINOSA, Daniela Castillo; ESPINOZA, Yanara Pavez. Et al. Frecuencia de antígenos del sistema sanguíneo $\mathrm{Rh}$ y del sistema Kellendonantes de sangre. Revista Cubana de Hematol, Inmunol y Hemoter, Chile, p.160-171, 31 fev. 2015.2 Disponível em: <https://www.medigraphic.com/pdfs/revcubheminmhem/rch-2015/rch152g.pdf>. Acesso em: 10 maios 2019.

SILVA, Célia R. G.; JORGE, Antonio O. C.; HIRTSCH, Iracema M. V.. Aloanticorpo anti-Diego (a) em gestante. Revista Brasileira de Hematologia e Hemoterapia, São José do Rio Preto, [s.p], out. 2004. Disponível em: <http://www.scielo.br/scielo.php?script=sci_arttext\&pid=S1516-4842004000400010>. Acesso em: 15 fev. 2019.

SANTOS, F. W. R.; MAGALHÃES, S. M. M.; Mota, R. M. S. et al. Aloimunização após transfusão de concentrado de hemácias em pacientes atendidos em um serviço de emergência. Revista Brasileira de Hematologia e Hemoterapia, São José do Rio Preto, v. 29, n. 4, [s.p.], out. 2007. Disponível em: <http://www.scielo.br/scielo.php?script=sci_arttext\&pid=S1516-

84842007000400009\&lng=en>. Acesso em: 08 jun. 2019.

VERRASTRO, Theresinha; LORENZI, Theresinha Ferreira; WENDEL NETO, Silvano. Hematologia e Hemoterapia: Fundamentos da Morfologia, Fisiologia, Patologia e Clínica. São Paulo: Atheneu, 2005. 303 p.

KOURY, W. K. Investigação da prevalência de anticorpos irregulares em doadores de sangue do Instituto Paranaense de Hemoterapia e Hematologia Ltda. 2018. 52 f. Dissertação (Mestrado) - Curso de Medicina, Faculdade de Medicina de Ribeirão Preto, Ribeirão Preto, 2018. 